\title{
Preterm delivery among first-time Mexico-born mothers: a binational population-based comparison of deliveries in California and Mexico
}

\author{
Sylvia Guendelman, ${ }^{1}$ Dorothy Thornton, ${ }^{2}$ Ricardo Perez-Cuevas, ${ }^{3}$ Julia Walsh ${ }^{1,2}$
}

\begin{abstract}
${ }^{1}$ Maternal and Child Health Program, School of Public Health, University of California, Berkeley, California, USA ${ }^{2}$ Division of Community Health and Human Development, School of Public Health, University of California, Berkeley, California, USA ${ }^{3}$ Division of Social Protection and Health, Inter-American Development Bank, Mexico City, Mexico
\end{abstract}

\section{Correspondence to} Dr Sylvia Guendelman, Maternal and Child Health Program, School of Public Health, 207J University Hall, University of California, Berkeley, CA 94720-7360, USA; sylviag@berkeley.edu

Received 13 February 2014 Revised 4 August 2014 Accepted 22 August 2014 Published Online First 10 September 2014

\section{CrossMark}

To cite: Guendelman $S$, Thornton D, Perez-Cuevas R, et al. J Epidemiol Community Health 2015:69:35-40.

\section{ABSTRACT}

Background While studies have attributed the favourable birth outcomes of Mexico-born mothers in the USA to a 'healthy immigrant effect' that confers protection to immigrants, a comparison of immigrants with the source population in Mexico has been lacking. We compared preterm delivery (PTD) rates of Mexicoborn immigrants who delivered in California with Mexico-born women who delivered in Mexico (WIMX) and with a subgroup who delivered in the five top immigrant sending states in Mexico.

Methods Using 2009 birth records, we selected all live-born singletons of primiparous WIMX (699 129) and immigrants in California (33 251). We examined the unadjusted and adjusted association between place of delivery and any PTD ( $<37$ weeks gestation), including PTD subcategories (early, moderate, late), using relative risks (RR) and $95 \% \mathrm{Cls}$. Multivariate models controlled for demographic and health system characteristics.

Results PTD rates were higher among immigrants in California (6.7\%) than WIMX (5.8\%) and compared to women in the sending states (5.5\%). The unadjusted risk of any PTD ( $R R=1.17$ (1.12 to 1.22)), early/ moderate PTD ( $<34$ weeks gestation; RR=1.27 (1.18 to 1.38)) and late PTD (34-36 weeks; RR=1.14 (1.08 to 1.19)) was higher for immigrants than for WIMX and remained higher when controlling for age, education and healthcare variables. Birth weight $<1500 \mathrm{~g}$ was also higher among immigrants ( $R R=1.27$ (1.14 to 1.44)). Similar patterns were observed when comparing women in the sending states.

Conclusions We found no evidence of a 'healthy immigrant effect'. Further research must assess the comparability of gestational-age data in Mexican and Californian birth certificates.

\section{INTRODUCTION}

Almost one in nine babies are born preterm (before 37 completed weeks gestation) annually in the USA ${ }^{1}$ a condition associated with a heightened risk of perinatal morbidity and mortality, childhood disabilities and adult onset of diseases. ${ }^{2}{ }^{3}$ In California, the state with the highest number of births, the preterm delivery (PTD) rate at 9.8/100 live births is lower than the national average. ${ }^{1}$ One important reason for the lower rates of preterm birth in California may be the high number of births to Mexico-born mothers. Previous studies have shown that Mexico-born mothers have more favourable birth outcomes compared with US-born Mexican-American women despite their lower socioeconomic (SES) resources, higher fertility and delayed access to prenatal care-a phenomenon known as the 'Latino paradox' ${ }^{4-7}$ Researchers have stated several hypotheses for the favourable outcomes of Mexico-born mothers. One is the 'healthy immigrant effect', which assumes that immigrants are a select group, with better health than the source population in Mexico, but this hypothesis has not been sufficiently tested with respect to perinatal outcomes. ${ }^{8} 9$ Another postulates that Mexican mothers in the USA may be protected against poor birth outcomes because of their residential proximity to coethnics, their robust social support systems and cultural orientation which is facilitated by living close to Mexico. ${ }^{10-12}$ A third explanation, for which there is limited evidence, attributes the disparities to reporting errors or other data quality issues. ${ }^{13}$ Yet another explanation is that immigrant status confers health protection, but that this protective effect weakens with increasing time in the USA and is not sustained in the next generation due to acculturation and insufficient integration to US society and/or due to the cumulative burdens of psychosocial stress, poverty and racism. ${ }^{14-17}$ If the assumption of a 'healthy immigrant effect' is correct, the outcomes of immigrants are expected to be more favourable than those of the population of origin.

Prior perinatal health research mostly compares Mexican mothers currently living in the USA. Mothers are largely differentiated by generational status, duration of US residence or language and empirical evidence from these studies on the health selection hypothesis is scarce and inconsistent. ${ }^{17} 18$ Studies mostly assume that it is the robust nature of immigrants and the selection of healthier migrants to the USA among lower SES immigrants that may predispose them on arrival to better birth outcomes, but studies lack information about immigrants before arrival. ${ }^{17} 1920$ Other studies of more general outcomes, such as a study of perceived health status among legal permanent residents in the USA, find less positive health selection among women than men and among immigrants from Mexico compared with other regions of origin, suggesting that the health selection hypothesis might not apply universally to all immigrants. ${ }^{19} 21$ Notably missing in this body of research is a crossnational perspective which relies on comparisons of immigrant mothers living in the USA with nonimmigrant mothers living in Mexico and considers the possible influences of the sending and receiving countries on immigrant health outcomes. ${ }^{8} 192022$ The source population in Mexico is crucial for evaluating the 'healthy immigrant effect' and to assess whether the favourable perinatal outcomes 
of immigrant mothers are attributable to individual and cultural attributes or to healthcare or other social and contextual characteristics.

In this population-based cross-sectional study, we compare PTD rates of Mexican immigrant mothers who deliver in California with those of mothers who were born and deliver in Mexico. We compare all births in Mexico and, more specifically, all births in the five sending states in Mexico with the highest proportion of immigration to California to determine whether immigrants have lower rates of PTD and hence demonstrate a 'healthy immigrant effect'. Since Mexicans are a heterogeneous population, a comparison with the population in the top sending states may reveal specific selection factors. For instance, if the birth patterns in these states are selected more by healthier women leaving to settle in California, we would expect wider disparities in PTD rates.

\section{METHODS}

Birth data were obtained from Certificados de Nacimiento de Mexico and California's Birth Statistical Master File and pooled into one single individual-level data set. We took advantage of the enhanced birth certificate and registration of births in Mexico, which was implemented in 2008. Study participants consisted of Mexico-born mothers who delivered a singleton live-born infant in Mexico and Mexico-born mothers (immigrants) who delivered a live-born singleton infant in California in 2009. To remove the effect of a previous PTD, which is a strong risk factor for PTD, ${ }^{23}$ we restricted the sample to primiparous women. In California, of all live births for which a birth certificate was available in $2009(\mathrm{n}=528625)$ to primiparous women $(n=208126), 33730$ were to immigrant mothers born in Mexico and of these, 33251 delivered a singleton baby between 20 and 44 weeks completed gestation. While in all of Mexico, including the sending states, of the live births for which a birth certificate was available in $2009(n=1971$ 662) to primiparous women $(n=713285), 699129$ Mexico-born women delivered a singleton infant at 20-44 weeks gestation. The 'sending state' comparison group further restricted these births to women residing in the Mexican states of Guerrero, Guanajuato, Jalisco, Michoacán and Oaxaca $^{24}(n=151729$; $22 \%)$.

\section{Variables}

We used obstetric estimates of gestational age from California birth certificates to estimate gestational age at delivery as this estimate best matched practices for estimating gestational age in Mexican birth certificates. Methods used to date gestation in Mexico are neither standardised nor routinely reported and include last menstrual period (LMP), ultrasound and fundal height. One study found that only $4.4 \%$ of pregnant women affiliated with the social security health system (Instituto Mexicano de Seguro Social, IMSS) in Mexico City had received an ultrasound. ${ }^{25}$ In California, obstetrical estimates are based on all perinatal factors (eg, fundal height, first pregnancy symptoms, LMP, heartbeat detection, quickening) and assessments such as ultrasound, but not the neonatal exam. Approximately $60 \%$ of pregnant women who underwent mid-pregnancy prenatal screening in 2007 had ultrasound dating information. ${ }^{26}$ PTD was defined as any birth delivered before 37 completed weeks gestation. Owing to different aetiologies and consequences, PTD was further categorised as early preterm ( $<32$ weeks gestation), moderate preterm (32-33 weeks) and late preterm (34-36 weeks). ${ }^{27}$ We also used very low birth weight (VLBW $<1500 \mathrm{~g}$ ) as a supplemental outcome because it is more easily measured, less prone to differential misclassification error and closely reflects patterns of preterm birth.

The key independent variable was place of residence (Mexico, top sending state in Mexico or California). Other independent variables consisted of demographic and healthcare characteristics available for each place and categorised broadly to enable cross-national comparisons. Demographic variables were maternal age (in years) and maternal education at time of delivery (less than high school, high school graduate or more). Two healthcare variables, namely type of health insurance used for prenatal care and trimester prenatal care initiated (first or second vs third/no care), were used as proxy measures of access to care. A third healthcare variable, mode of delivery (caesarean (c-section) or vaginal), was included because hospital practices and obstetric management can play an important role in delaying deliveries and reducing late preterm births. ${ }^{28}$ Insurance categories included uninsured, publicly insured (IMSS Oportunidades and Seguro Popular in Mexico and Medi-Cal and other government funded programmes in California) and social health insurance or privately insured (covered by IMSS and Instituto de Seguridad y Servicios Sociales de los Trabajadores del Estado (ISSSTE), Petroleos Mexicanos (PEMEX) and army and navy (Sedena and Semar) in Mexicosystems that require a private or mandatory contribution (through payroll taxes) to finance health services and members of private health plans in California).

\section{Data analysis plan}

Statistical analyses were performed using SAS V.9.2 (StatCorp LP, College Station, Texas, USA). Bivariate analyses examined the crude association between place of delivery (Mexico and California) and any PTD, early, moderate, late PTD and VLBW. The relative risks (RR) and their 95\% CIs were calculated for immigrant California women compared with WIMX and to the subgroup of women from Mexican sending states for each PTD measure. Within each place of delivery, we examined the frequency distribution of covariates for women who had an early or moderate PTD, late PTD or term delivery. We combined early and moderate PTD into one category labelled early/moderate PTD to increase power. We restricted our analysis to women 18 years or older in order to improve the interpretability of the education covariate. To examine adjusted RRs for place of delivery and 95\% CIs, we used a generalised linear model with log link and binomial probability. In our main effects model, we adjusted for age, educational level (dichotomised), prenatal care initiation (dichotomised), delivery mode and insurance type. In additional analyses, we further controlled for interactions between place and other covariates. Covariates that significantly interacted with place were used to define relevant subpopulations. The effect and significance of place within each subpopulation was examined.

This study was approved by the ethics Committee at UC Berkeley and the California Committee for the Protection of Human Subjects, Project No.12-08-0681. Since Mexican data are public, no approval was sought.

\section{RESULTS}

Rates of PTD were higher among immigrants in California $(6.7 \%)$ compared to WIMX overall $(5.8 \%$; RR=1.17; $(1.12$ to 1.22); table 1). When broken down by PTD categories, the risk for early PTD at less than 32 weeks gestation $(\mathrm{RR}=1.50 ;(1.35$ to 1.66)) and late PTD (at 34-36 weeks gestation; $R R=1.14$; (1.09 to 1.20$)$ ) was higher for immigrant women, whereas the risk of moderate PTD at 32-33 weeks gestation was similar. 
Table 1 Rates of preterm delivery (PTD) and very low birth weight (VLBW) among women born in Mexico delivering in California (immigrants) and Mexico (WIMX) including women in Mexican immigrant sending states in 2009: relative risks (RR) and $95 \% \mathrm{Cl}$

\begin{tabular}{|c|c|c|c|c|c|c|c|c|}
\hline \multirow[b]{2}{*}{ PTD* (in weeks) and VLBW } & \multicolumn{2}{|c|}{ Immigrants } & \multicolumn{2}{|l|}{ WIMX } & \multicolumn{2}{|c|}{ MX sending states } & \multirow{2}{*}{$\begin{array}{l}\text { RR immigrant: } \\
\text { WIMX 95\% CI }\end{array}$} & \multirow{2}{*}{$\begin{array}{l}\text { RR immigrant: } \\
\text { MX sending states } 95 \% \mathrm{Cl}\end{array}$} \\
\hline & $\mathrm{N}$ & Per cent & $\mathbf{N}$ & Per cent & $\mathrm{N}$ & Per cent & & \\
\hline Any PTD & 2239 & 6.73 & 40254 & 5.76 & 8303 & 5.47 & 1.17 (1.12 to 1.22$)$ & 1.23 (1.17 to 1.29$)$ \\
\hline Early PTD (<32) & 386 & 1.23 & 5456 & 0.82 & 1104 & 0.73 & 1.50 (1.35 to 1.66$)$ & $1.60(1.42$ to 1.79$)$ \\
\hline Moderate PTD (32-33) & 233 & 0.75 & 4823 & 0.73 & 1000 & 0.66 & $1.03(0.90$ to 1.17$)$ & $1.06(0.92$ to 1.23$)$ \\
\hline Late PTD (34-36) & 1620 & 4.87 & 29975 & 4.29 & 6199 & 4.09 & 1.14 (1.08 to 1.19$)$ & $1.19(1.13$ to 1.26$)$ \\
\hline Term (37-42) & 30988 & 93.19 & 658561 & 94.20 & 143360 & 94.48 & 0.99 (0.99 to 0.99$)$ & $0.99(0.98$ to 0.99$)$ \\
\hline Post-term (43-44) & 24 & 0.07 & 314 & 0.04 & 66 & & Not calculated & Not calculated \\
\hline VLBW & 335 & 1.01 & 5503 & 0.79 & 1146 & 0.76 & $1.27(1.14$ to 1.42$)$ & $1.33(1.18$ to 1.50$)$ \\
\hline
\end{tabular}

Denominator for any PTD, term deliveries and VLBW is all deliveries.

${ }^{*}$ Denominator for early, moderate and late PTD is the outcome of interest and term deliveries only.

The results that are bolded denote statistical significance at $p<=0.05$.

Disparities were even sharper when comparing immigrants to women in the Mexican sending states, particularly for early PTD (RR=1.70; (1.51 to 1.90$)$ ).

Demographic and healthcare characteristics among women 18 years or older differed more between California and Mexico than within PTD categories in each place (table 2). Compared to immigrants, WIMX delivered their first child at a younger age, were less likely to have a high school diploma or some college at the time of delivery and to start prenatal care in the first trimester. Furthermore, WIMX were less likely to have public insurance and more likely to be uninsured and to deliver by c-section compared to immigrants in California.

Within California, immigrant women who delivered prior to 34 weeks were older, less educated, slightly more likely to have private insurance, to start prenatal care early and far more likely to deliver by c-section than those who delivered at term (table 2). A similar pattern but less pronounced was found for women delivering late preterm compared to term. In Mexico, women who delivered prior to 34 weeks gestation or had a late PTD were, as in California, more likely to be older, have social health insurance or private insurance and deliver by c-section than those who delivered at term. However, in contrast to women in California, they were also more likely to be college educated and have late or no prenatal care. Similar patterns were found among women in the Mexican sending states. Women in sending states differed from those in all of Mexico in that they had lower education, were far less likely to be uninsured and more likely to have public insurance and to start prenatal care early (table 2).

The multivariate models in table 3 show that when controlling for covariates, the risk of any PTD $(\mathrm{RR}=1.25$ (1.19 to 1.31)), early/moderate PTD $(\mathrm{RR}=1.43(1.30$ to 1.57$))$ and late PTD $(\mathrm{RR}=1.20$ (1.13 to 1.27$)$ ) was higher for immigrants than for WIMX. The risk of VLBW was also markedly higher for immigrants compared to WIMX $(\mathrm{RR}=1.43$ (1.26 to 1.61). Similar patterns were observed when comparing immigrants to women delivering in the Mexican sending states. For immigrants, the risk of any PTD was 27\% higher (1.20-1.34), of early/moderate PTD was 44\% higher (1.29-1.60), of late PTD was $22 \%$ higher (1.15-1.30) and of VLBW was 36\% higher (1.18-1.58).

We found significant interactions with place and insurance type and trimester prenatal care initiated in our models for any PTD and with place and delivery mode and insurance type for late PTD (data not shown). However, in no subpopulation was the risk of PTD for immigrants significantly lower compared to women in Mexico. Interactions were also found for delivery mode and trimester prenatal care initiated with place for early/ moderate PTD and VLBW (data not shown), but only among the subpopulation who delivered vaginally and had late prenatal care were immigrants at lower risk for PTD compared to WIMX. Notably, this subpopulation represents only 3\% of all women. Interaction models restricted to women in Mexican sending states also did not show a significantly lower risk of outcomes for immigrants except for a lower risk of late PTD among women aged 32 years or older who delivered by c-section. This subpopulation represented $7 \%$ of the total.

\section{DISCUSSION}

In this study of PTD to first-time mothers born in Mexico, we found no evidence of a 'healthy immigrant effect' among mothers delivering in California. In fact, we found that immigrant women in California 18 years or older stand a higher risk of any PTD, a PTD occurring prior to 34 weeks and of a late PTD compared with women who were born and delivered in Mexico, in unadjusted and adjusted analyses. Furthermore, the risk of PTD among immigrants was similar when compared with Mexican women from the high migrant sending states, suggesting that these birth patterns are not more selected by healthier women leaving to settle in California. The risk for VLBW was also markedly higher among immigrants compared to women in Mexico and to women in sending states, which was consistent with our findings for early PTD.

The higher PTD rates among immigrants in California compared with those in Mexico are consistent with 2010 country rates (12\% in the US vs $7.3 \%$ in Mexico) ${ }^{29}$ and with 2009 PTD rates in US border states $(11.6 \%)$ versus Mexican border states $(6.7 \%){ }^{30}$ Nonetheless, the findings are surprising given that immigrant women in California, regardless of legal status, are largely insured for pregnancy-related services while about one in three WIMX (and about 22\% in sending states) are uninsured. The higher rates of insurance for prenatal care, earlier initiation of prenatal care, along with a well-organised regionalised system of perinatal care in California, should lead to better access to more risk-appropriate levels of medical care. The earlier start of prenatal care among immigrants in California may contribute to better establishment and monitoring of gestational age. Although c-sections are positively associated with late preterm births occurring between 34 and 36 weeks gestation, ${ }^{31}$ we found much lower rates of c-sections among immigrants than women in Mexico for both term births (31\% in California vs $50 \%$ in all Mexico and $51 \%$ in sending states) and for preterm births (39\% in California vs $60 \%$ in all Mexico and $61 \%$ in sending states). Additionally we found that for the subpopulation of women older than 31 years who delivered by c- 
Table 2 Demographic and health characteristics of immigrants and WIMX, including women delivering in Mexican immigrant sending states in 2009 aged 18 or older, by gestational age categories

\begin{tabular}{|c|c|c|c|c|c|c|c|c|c|}
\hline & \multicolumn{3}{|l|}{ Immigrant } & \multicolumn{3}{|l|}{ WIMX } & \multicolumn{3}{|c|}{$\mathrm{MX}$ sending states } \\
\hline & $\begin{array}{l}\text { Early/mod } \\
\text { PTD } \\
\mathrm{N}=572\end{array}$ & $\begin{array}{l}\text { Late } \\
\text { PTD } \\
\mathrm{N}=1471\end{array}$ & $\begin{array}{l}\text { Term } \\
\mathrm{N}=28484\end{array}$ & $\begin{array}{l}\text { Early/moderate } \\
\text { PTD } \\
\mathrm{N}=7905\end{array}$ & $\begin{array}{l}\text { Late PTD } \\
\mathrm{N}=23288\end{array}$ & $\begin{array}{l}\text { Term } \\
\mathrm{N}=512090\end{array}$ & $\begin{array}{l}\text { Early/mod } \\
\text { PTD } \\
\mathrm{N}=1597\end{array}$ & $\begin{array}{l}\text { Late } \\
\text { PTD } \\
\mathrm{N}=4794\end{array}$ & $\begin{array}{l}\text { Term } \\
\mathrm{N}=111507\end{array}$ \\
\hline \multicolumn{10}{|l|}{ Age } \\
\hline $18-19(\%)$ & 13.64 & 15.23 & 14.92 & 23.68 & 23.87 & 27.04 & 23.17 & 22.19 & 26.52 \\
\hline $20-24(\%)$ & 32.87 & 37.39 & 41.39 & 38.39 & 38.64 & 42.40 & 38.20 & 38.90 & 43.27 \\
\hline $25-29(\%)$ & 23.60 & 24.81 & 24.83 & 21.33 & 21.27 & 19.62 & 21.67 & 21.69 & 19.76 \\
\hline $30-34(\%)$ & 18.53 & 13.60 & 12.50 & 10.52 & 10.38 & 7.78 & 10.02 & 10.30 & 7.43 \\
\hline $35+(\%)$ & 11.36 & 8.97 & 6.36 & 6.07 & 5.84 & 3.17 & 5.95 & 5.90 & 3.02 \\
\hline Average age (years) & 26.3 & 25.4 & 24.8 & 24.1 & 24.0 & 23.1 & 24.00 & 24.00 & 23.01 \\
\hline Age range (in years) & $18-47$ & $18-45$ & $18-47$ & $18-55$ & $18-56$ & $18-58$ & $18-45$ & $18-52$ & $18-58$ \\
\hline Education (n missing) & (25) & (46) & (1004) & (158) & (372) & (7513) & (28) & (54) & (1470) \\
\hline 8th grade or less (\%) & 19.38 & 16.77 & 15.47 & 19.93 & 17.69 & 18.91 & 29.08 & 25.36 & 26.24 \\
\hline No high school diploma (\%) & 27.24 & 25.40 & 26.06 & 34.54 & 34.59 & 36.78 & 32.76 & 34.73 & 36.47 \\
\hline High school diploma (\%) & 33.27 & 33.12 & 33.89 & 24.84 & 25.69 & 25.89 & 19.57 & 20.70 & 21.65 \\
\hline Some college (\%) & 20.11 & 24.70 & 24.57 & 20.68 & 22.02 & 18.42 & 18.67 & 19.16 & 15.61 \\
\hline $\begin{array}{l}\text { Insurance for prenatal care } \\
\text { (n missing) }\end{array}$ & (4) & (11) & (213) & (401) & (1174) & (23 305) & (64) & (155) & (3315) \\
\hline Uninsured (\%) & 4.05 & 5.27 & 4.29 & 33.56 & 31.84 & 33.31 & 22.18 & 21.97 & 24.04 \\
\hline $\begin{array}{l}\text { Social health insurance or } \\
\text { privately insured (\%) }\end{array}$ & 21.65 & 19.79 & 18.95 & 39.49 & 38.85 & 32.77 & 34.51 & 34.77 & 28.23 \\
\hline Publicly insured (\%) & 74.30 & 74.93 & 76.76 & 26.96 & 29.30 & 33.92 & 43.31 & 43.26 & 47.73 \\
\hline Trimester PNC began ( $\mathrm{n}$ missing) & (11) & (31) & (300) & (200) & $(451)$ & (8433) & (42) & (88) & $(1885)$ \\
\hline First (\%) & 84.85 & 80.76 & 79.75 & 75.29 & 76.95 & 76.38 & 78.83 & 79.41 & 78.93 \\
\hline Second $(\%)$ & 12.12 & 14.31 & 15.48 & 16.81 & 17.22 & 17.91 & 15.05 & 16.06 & 16.34 \\
\hline Third or none (\%) & 3.03 & 4.93 & 4.77 & 7.90 & 5.82 & 5.71 & 6.17 & 4.53 & 4.72 \\
\hline Caesarean section ( $\mathrm{n}$ missing) & $(0)$ & (0) & (0) & (15) & (61) & $(1028)$ & (3) & (9) & (58) \\
\hline$(\%)$ & 47.55 & 35.55 & 30.54 & 58.02 & 61.33 & 50.19 & 56.50 & 62.65 & 50.71 \\
\hline
\end{tabular}

Immigrant, Mexico-born women delivering in California; MX, Mexico; PTD, preterm delivery; WIMX, Mexico-born women delivering in Mexico.

section, the risk of late PTD was lower in California compared with women in the sending states. According to WHO, population level caesarean rates should not exceed $10-15 \%$ of births and only be performed given a medical indication. ${ }^{32}$ Further research should assess the very high rates of c-sections in Mexico.

The higher rates of PTD among immigrants could perhaps be partly explained by the lower rates of fetal deaths in California. We estimate fetal deaths at 20 or more weeks gestation to Mexican immigrants in California at 3.5 (B Anderson, personal

Table 3 Adjusted relative risks (RR) and $95 \% \mathrm{Cl}$ of any preterm delivery (PTD), early/moderate or late PTD and very low birth weight (VLBW) among Mexican immigrants versus women in Mexico (WIMX) and women in immigrant sending states in Mexico (aged 18 years or older) in 2009

\begin{tabular}{|c|c|c|c|c|}
\hline & \multicolumn{2}{|c|}{ Immigrant vs WIMX } & \multicolumn{2}{|c|}{$\begin{array}{l}\text { Immigrant vs MX } \\
\text { sending states }\end{array}$} \\
\hline & $\mathbf{R R}^{*}$ & $95 \% \mathrm{Cl}$ & $\mathbf{R R}^{*}$ & $95 \% \mathrm{Cl}$ \\
\hline Any PTD & 1.25 & 1.19 to 1.31 & 1.27 & 1.20 to 1.34 \\
\hline Early/moderate PTD & 1.43 & 1.30 to 1.57 & 1.44 & 1.29 to 1.60 \\
\hline Late PTD & 1.20 & 1.13 to 1.27 & 1.22 & 1.15 to 1.30 \\
\hline VLBW & 1.43 & 1.26 to 1.61 & 1.36 & 1.18 to 1.58 \\
\hline
\end{tabular}

\footnotetext{
${ }^{*}$ Adjusted for age, education, trimester prenatal care initiated, insurance type and
} mode of delivery. communication and special runs from California Perinatal Profiles Project UC Berkeley) versus 10.8/1000 births (live plus fetal deaths) for WIMX ${ }^{33}$ in 2009. The rate for Mexico may be conservative given the substantial under-reporting, ${ }^{34}$ but these higher rates indicate less chances of live birth resulting from premature deliveries in Mexico compared with California. We estimate that if even $50 \%$ of fetal deaths could be prevented in Mexico such that they would result in a preterm live birth, the overall PTD rate would increase to $6.3 \%$, which is still slightly lower than the $6.7 \%$ rate among immigrants.

Higher rates of PTD among immigrants in California than WIMX could be an artefact of differences in gestational age ascertainment. The more widespread use of early ultrasound could lower estimates of gestational ages in California, resulting in fewer babies categorised as term. Since there are no national estimates of ultrasound use in Mexico, to address this issue, we assumed that gestational age for all term births in Mexico weighing less than the 10th centile mean birth weight for babies delivered at 36 weeks gestation in California was misascertained. Under this assumption, the directionality of the RR of PTD for immigrants versus women in Mexico changes $(R R=0.94(0.97$ to 0.98$)$ ), while the RR for immigrants versus women in sending states becomes comparable $(\mathrm{RR}=0.98(0.94$ to 1.02)). Further studies must assess the comparability of Mexican and Californian birth certificate gestational age data. While the selection of a gestational dating method has implications for studying preterm, studies comparing LMP-based estimates with ultrasound-based estimates have found that LMP 
underestimates the date of delivery by 2-3 days on average. ${ }^{35}$ Notably, we found that rates of VLBW, a measure that is less prone to differential misclassification error, were also significantly higher among immigrants.

This study had other limitations. In this cross-sectional analysis, we cannot establish causation. We also could not examine the effects of return migration. The higher rates of PTD among immigrants could have been due to the lower probability of high-risk mothers returning to their home country if they believed that they had better access to quality healthcare in the USA. ${ }^{36}$ Conversely, immigrants could have been more likely to return to Mexico if they had more dependable sources of social support. Further research is required in this area.

Analysis did not account for unregistered births. In California, 99\% of births occur in hospital, ${ }^{34} 37$ and $94.4 \%$ of births in Mexico are delivered in hospitals or clinics and presumably are registered. ${ }^{30} 38$ Maternal complications that are known risk factors for PTD, such as pre-pregnancy obesity, antenatal haemorrhage and preeclampsia, were not included because this information is lacking in Mexican birth certificates. Adjusting for population and healthcare factors must be performed cautiously, since the same factors may not have the same effects in California and in Mexico. For instance, WIMX deliver their first baby at earlier ages than Mexico-born women in California, perhaps due to the different social expectations related to family formation or to childbearing delays caused by migration. Similarly, educational attainment at the time of delivery may be a different marker of SES depending on when the highest degree was obtained. WIMX may receive less recommended prenatal care than those in the USA or may start prenatal care later due to healthcare and economic barriers that differ from those in California. ${ }^{25}$ Furthermore, we lacked information on duration of residence and legal status of immigrants. Approximately 900000 undocumented women, mostly from Mexico, lived in California in 2009. ${ }^{39}$ Undocumented immigrants experience disproportionately low SES, difficulty with English and with healthcare access, stressors which may contribute to poor birth outcomes. Given inconsistent evidence, future studies must determine whether immigrants who reside legally in California are more likely to exhibit a 'healthy immigrant effect'. ${ }^{40}$ The strengths of this study were that it was population-based and included data from recent birth certificates in Mexico, which have improved reporting and quality control of data.

In sum, our findings show that primiparous Mexico-born mothers stand a higher risk of PTD if they deliver in California compared to Mexico; however, further research must assess the comparability of gestational age in birth certificates and the extent to which our findings apply to all Mexicans-documented and undocumented-living in the USA, and to Mexican mothers living in other countries. Assessing a wider array of outcomes may provide a clearer picture; nonetheless, our analysis finds little evidence of a healthy migrant effect for PTD or VLBW, even when compared with women from sending states. This finding has clinical and policy implications. Preterm births in the USA are associated with enormous costs of care to families and society. ${ }^{31}$ From a policy standpoint, the USA in recent decades has experienced the biggest immigration wave in its history, especially from Mexico. ${ }^{42}$ Immigrants from Mexico tend to have higher shares of women of childbearing age and higher birth rates than the US-born population, and most of the growth in the Latino population is currently driven by births rather than immigration. ${ }^{42}$ Understanding how to improve birth outcomes of Mexican women in the USA is of primary importance.

\section{What is already known on this subject}

Numerous studies show that foreign birth confers protection against adverse birth outcomes among Mexican immigrants in the USA. While previous studies compare immigrants to US-born populations, evidence comparing immigrants to the source population in Mexico is lacking.

\section{What this study adds}

In this first population-level study to assess preterm delivery among primiparous Mexico-born immigrant women delivering in California and in Mexico, including delivery in the top five Mexican immigrant sending states, we found that women stand a higher risk of preterm delivery if they deliver in California. Our analysis finds little evidence of a 'healthy immigrant effect' for preterm birth. Further research must assess the comparability of gestational age in birth certificates from Mexico and California and the extent to which our findings apply to all Mexican immigrants - documented and undocumented-living in the USA, and to Mexican women living in other countries.

Acknowledgements Authors wish to thank Nap Hosang, MD for his clinica insights and to Maureen Lahiff for recommendations on statistical analysis.

Contributors SG conceptualised and designed the study, analysed and interpreted the data, wrote the manuscript, is the guarantor of the paper, accepts full responsibility for the work and the conduct of the study and controlled decision to publish; DT was the primary analyst and helped with the study design, interpretation and writing; RP-C provided the Mexican data and helped with interpretation of findings and editing; JW contributed to the study design, interpretation and preparation of the manuscript.

Funding This paper was funded in part by an award to SG and JW from the Robert Wood Johnson Foundation Health and Society Scholars Program at UC Berkeley.

Competing interests This paper was funded in part by an award to SG and JW from the Robert Wood Johnson Foundation Health and Society Scholars Program.

Ethics approval This study was approved by the ethics Committee at UC Berkeley and the California Committee for the Protection of Human Subjects, Project No.12-08-0681.

Provenance and peer review Not commissioned; externally peer reviewed. Data sharing statement Data are publicly available.

\section{REFERENCES}

1 Martin J, Hamilton B, Ventura S, et al. Births: final data for 2010. Nat/ Vital Stat Rep 2012;61:1-72. [28 Aug 2012] http://www.cdc.gov/nchs/data/nvsr/nvsr61/ nvsr61_01.pdf

2 Committee on Understanding Premature Birth and Assuring Healthy Outcomes. Preterm birth: causes, consequences, and prevention. 1st edn. Washington, DC: National Academies Press, 2007. http://www.ncbi.nlm.nih.gov/books/NBK11374/

3 Goldenberg RL, Culhane JF, lams JD, et al. Epidemiology and causes of preterm birth. Lancet 2008;371:75-84.

4 Guendelman S, Gould JB, Hudes M, et al. Generational differences in perinatal health among the Mexican American population: findings from HHANES 1982-84. Am J Public Health 1990;80(Suppl):61-5.

5 Rumbaut GR, Weeks JR. Unraveling a public health enigma: why do immigrants experience superior perinatal health outcomes? Res Sociol Health Care 1996;13:335-88.

6 Singh GK, Yu SM. Adverse pregnancy outcomes: differences between US- and foreign-born women in major US racial and ethnic groups. Am J Public Health 1996;86:837-43 
7 Fuentes-Afflick E, Lurie P. Low birth weight and Latino ethnicity: examining the epidemiologic paradox. Arch Pediatr Adolesc Med 1997;151: 665-74.

8 Palloni A, Arias E. Paradox lost: explaining the Hispanic adult mortality advantage. Demography 2004;41:385-415.

9 Abraído-Lanza AF, Dohrenwend BP, Ng-Mak DS, et al. The Latino mortality paradox: a test of the salmon bias and healthy migrant hypotheses. Am J Public Health 1999:89:1543-8.

10 Urquia ML, Glazier RH, Blondel B, et al.; ROAM collaboration. International migration and adverse birth outcomes: role of ethnicity, region of origin and destination. J Epidemiol Community Health 2010;64:243-51.

11 Osypuk TL, Bates LM, Acevedo-Garcia D. Another Mexican birthweight paradox? The role of residential enclaves and neighborhood poverty in the birthweight of Mexican-origin infants. Soc Sci Med 2010;70:550-60.

12 Guendelman S, Malin C, Herr-Harthorn B, et al. Orientations to motherhood and male partner support among women in Mexico and Mexican-origin women in the United States. Soc Sci Med 2001;52:1805-13.

13 Eschbach K, Kuo YF, Goodwin JS. Ascertainment of Hispanic ethnicity on California death certificates: implications for the explanation of the Hispanic mortality advantage. Am J Public Health 2006;96:2209-15.

14 Scribner R, Dwyer JH. Acculturation and low birthweight among Latinos in the Hispanic HANES. Am J Public Health 1989;79:1263-7.

15 Acevedo-Garcia D, Soobader MJ, Berkman LF. Low birthweight among US Hispanic Latino subgroups: the effect of maternal foreign-born status and education. Soc Sci Med 2007;65:2503-16.

16 Kirby RS. Perinatal outcomes and nativity: does place of birth really influence infant health? Birth 2011;38:354-6.

17 Wingate MS, Alexander GR. The healthy migrant theory: variations in pregnancy outcomes among US-born migrants. Soc Sci Med 2006;62:491-8.

18 Leslie J, Diehl S, Galern S. A comparison of birth outcomes among US-born and non-US born Hispanic women in North Carolina. MCHJ 2006:10:33-7.

19 Acevedo-Garcia D, Sanchez-Vaznaugh E, Viruell-Fuentes E, et al. Integrating social epidemiology into immigrant health research: a cross-national framework. Soc Sci Med 2012;75:2060-8.

20 Rubalcava $L$, Teruel $G$, Thomas $D$, et al. The healthy migrant effect: new findings from the Mexican family life survey. AJPH 2008;98:78-84.

21 Atresh IR, Frank R. Healthy selection among new immigrants. Am J Public Health 2008;98:2058-64.

22 Acevedo-Garcia D, Almeida J. Special issue introduction: place, migration and health. Soc Sci Med 2012;75:2055-9.

23 lams JD, Berghella V. Care for women with prior preterm birth. Am J Obstet Gynecol 2010;203:89-100.

24 El Colegio de la Frontera Norte, Secretaria del Trabajo y Prevision Social, Consejo Nacional de Poblacion, Instituto Nacional de Migracion, Secretaria de Relaciones Exteriores. Encuesta sobre Migración de la Frontera Norte (EMIF) 2009-2013. Downloaded February 272014.
25 Doubova S, Perez-Cuevas R, Ortiz-Panozo E, et al. Evaluation of the quality of antenatal care using electronic health record information in family medicine clinics of Mexico City. BMC Pregnancy Childbirth 2014;14:168-83.

26 Dietz PM, England LJ, Callaghan WM, et al. A comparison of LMP-based and ultrasound-based estimates of gestational age using linked California livebirth and prenatal screening records. Paediatr Perinat Epidemiol 2007;21(Suppl 2):62-71.

27 Kramer MS, Demissie K, Yang H, et al. The contribution of mild and moderate preterm birth to infant mortality. Fetal and Infant Health Study Group of the Canadian Perinatal Surveillance System. JAMA 2000;284:843-9.

28 Davidoff MJ, Dias T, Damus K, et al. Changes in the gestational age distribution among U.S. singleton births: impact on rates of late preterm birth, 1992 to 2002. Semin Perinatol 2006;30:8-15.

29 World Health Organization and partners. Born too soon. The Global Action Report on Preterm Birth. http://www.who.int/maternal_child_adolescent/documents/born_ too_soon/en/

30 McDonald J, Mojarro O, Sutton $\mathrm{P}$, et al. A binational overview of reproductive health outcomes among US Hispanic and Mexican women in the border region. Prev Chronic Dis 2013;10:1-13.

31 Engle WA, Kominiarek MA. Late preterm infants, early term infants, and timing of elective deliveries. Clin Perinatol 2008;35:325-41.

32 UNICEF, World Health Organization, United Nations Population Fund. Guidelines for monitoring the availability and use of obstetric services. New York: United Nations Children's Fund, 1997.

33 Instituto Nacional de Estadistica y Geografia (INEGI). Boletin de Estadisticas Vitales 2009. Aguascalientes, México, 2009.

34 Dirección General de Información en Salud (DGISS). Certificado de Muerte Fetal. http:/l www.dgis.salud.gob.mx/certificados/comuertefetal.html (accessed 19 Aug 2013).

35 Savitz D, Terry J, Dole N, et al. Comparison of pregnancy dating by last menstrual period, ultrasound scanning and their combination. Am J Obstet Gynecol 2002;187:1660-6.

36 Ceballos M, Palloni A. Maternal and infant health of Mexican immigrants in the USA: the effects of acculturation, duration, and selective return migration. Ethn Health 2010;15:377-96.

37 MacDorman MI, Mathews MS, Declercq E. Home births in the US, 1990-2009. NCHS Data Brief, No. 84, January 2012. http://www.cdc.gov/nchs/data/databriefs/db84.pdf

38 Secretaría de Salud de México. Subsistema de Informacion sobre Nacimientos (SINAC). Manual de llenado del certificado de nacimiento. 2007. http://www.sinais. salud.gob.mx/descargue/pdf/CN_Manualllenado.pdf (accessed 28 Jan 2013).

39 Wallace S, Torres J, Sodegh-Nobari T, et al. Undocumented immigrants and health care reform: final report to The Commonwealth Fund. UCLA Center for Health Policy Research. 30 August 2012.

40 Dang B, Van Dessel L, Hanke J, et al. Birth outcomes among low-income womendocumented and undocumented. Perm J 2011;15:39-43.

41 Kelaher M, Jessop DJ. Differences in low birthweight among documented and undocumented foreign-born and US-born Latinas. Soc Sci Med 2002;55:2171-5.

42 Taylor P, Cohn D'V. A Milestone en Route to a Majority Minority Nation. PEW Research Social and Demographic Trends, 7 Nov 2012. http://www.pewsocialtrends. org/2012/11/07/a-milestone-en-route-to-a-majority-minority-nation/ 